\title{
Política de masas para una estrategia revolucionaria: PRT-ERP, 1973-1976
}

\section{Mass policy for a revolutionary strategy: PRT-ERP, 1973-1976}

\author{
Violeta Ayles Tortolini \\ Consejo Nacional de Investigaciones Científicas y Técnicas \\ Instituto de Ciencias Humanas, Sociales y Ambientales
}

(Argentina)

atvioleta@hotmail.com

\begin{abstract}
Resumen
En este trabajo analizamos la política con la que el PRT-ERP desarrolló su inserción e influencia en sectores de masas. Exploramos su apuesta de frente político, el Frente Antiimperialista y por el Socialismo (FAS), y las herramientas de intervención en los frentes de masas. Con esta denominación hacemos referencia a los escenarios en los que el PRT-ERP participaba a través de agrupaciones y corrientes, como el frente sindical, estudiantil o cultural: el Movimiento Sindical de Base (MSB), la Juventud Guevarista (JG) y el Frente Antiimperialista de Trabajadores de la Cultura (FATRAC). En cada caso reconstruiremos la experiencia histórica - buscando identificar datos respecto de sus orígenes, composición, principales hitos, etc.-, para luego dar paso a la perspectiva política con la que el PRT-ERP los impulsaba.
\end{abstract}

Palabras Clave: Historia reciente - PRT-ERP - Inserción. 


\begin{abstract}
This paper analyzes the policy with wich the PRT-ERP achieved its integration and influence in mass sectors. We explore its intends to act through a political front - the Frente Antiimperialista por el Socialismo (FAS)-, and its intervention tools on "mass fronts". With this nomination we refer to scenarios in which the PRT-ERP was involved through different groups and political spaces, like the union front, the student front and the cultural front: the Movimiento Sindical de Base Base (MSB), the Juventud Guevarista (JG) and the Frente Antiimperialista de Trabajadores de la Cultura (FATRAC). In each case we will try to reconstruct the historical experience, looking to identify its origins, composition and political milestones. Then we wull give space to the political perspective by which they were driven.
\end{abstract}

Key Words: Recent history - PRT-ERP - Insertion.

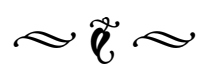

\section{Introducción}

En este trabajo analizaremos las concepciones políticas con las que el Partido Revolucionario de los Trabajadores - Ejército Revolucionario del Pueblo (PRT-ERP) ${ }^{1}$ desarrolló su inserción e influencia en sectores de masas. $\mathrm{Si}$ bien es cierto que la lucha armada ocupó un lugar central en el proyecto perretista, debido a su estrategia de guerra civil revolucionaria, no menos cierto es que impulsó una amplia variedad de espacios de participación a fin de

1. El PRT (1965-1976) fue un partido marxista, producto de la confluencia entre el Frente Revolucionario Indoamericano Popular (FRIP) y Palabra Obrera (PO), que luchó por la revolución socialista en Argentina. Su estrategia, definida como "guerra civil revolucionaria" condujo a la práctica de la lucha armada para la toma del poder. A partir de 1970 contó con una herramienta militar: el ERP. Definió a la clase obrera como sujeto revolucionario desarrollando una política de inserción fabril denominada proletarización. Logró constituirse en más de diez provincias y protagonizó acciones armadas. Sus militantes, como los/as de otras organizaciones revolucionarias, estuvieron en la mira de la Triple A y de la última dictadura. Sus principales dirigentes, Mario Roberto Santucho, Domingo Menna y Benito Urteaga, se encuentran desaparecidos. abordar las diversas esferas de la vida de los sectores populares.

Exploraremos su apuesta de frente político, el Frente Antiimperialista y por el Socialismo (FAS), y las herramientas de intervención en los frentes de masas. Con esta denominación hacemos referencia a los escenarios en los que el PRT-ERP participaba a través de agrupaciones y corrientes, como el frente sindical, estudiantil o cultural, el Movimiento Sindical de Base (MSB), la Juventud Guevarista (JG) y el Frente Antiimperialista de Trabajadores de la Cultura (FATRAC). En cada caso, reconstruiremos la experiencia histórica -identificando sus orígenes, composición y principales hitos- $\mathrm{y}$ analizaremos la política con la que el PRTERP los impulsaba. Otras experiencias no analizadas en este artículo se desarrollaron en el plano comunicacional -diario El Mundo- y de defensa de presos/as políticos/as-Comisión de Familiares de Presos Políticos, Estudiantiles y Gremiales (COFAPPEG).

E1 recorte temporal responde a los años de desarrollo de estas experiencias (con la 
excepción de algunas políticas culturales que dieron sus primeros pasos unos años antes). E1 restablecimiento del régimen constitucional en 1973 yla política de democratización impulsada por el presidente Héctor Cámpora, luego de siete años de dictadura, abrió un margen que fue aprovechado por las organizaciones revolucionarias para la estructuración de agrupaciones y corrientes legales. Por ello, no es casual que las experiencias del FAS, MSB y JG hayan tenido lugar a partir de 1973. Del mismo modo que su ocaso estuvo marcado por la creciente política represiva -legal y extralegal- impulsada por los gobiernos de Juan Domingo Perón y María Estela Martínez.

$\mathrm{Si}$ bien estas herramientas lograron desarrollarse en diversas zonas del país, han recibido escasa atención historiográfica. En las historias generales sobre el PRT-ERP emergen referencias a los frentes de masas, pero no se expone una descripción densa de los mismos, a excepción de la obra de Pablo Pozzi. ${ }^{2}$ En cuanto a la bibliografía específica, en el caso de las políticas culturales, existe una masa crítica considerable, mientras que resulta escasa en relación al FAS y el MSB y no existen producciones sobre JG.

Este trabajo se inscribe en la reciente tendencia a investigar el desarrollo perretista en los frentes de masas, con el objetivo de ofrecer una descripción panorámica que aporte al conocimiento de las diversas formas de inserción del PRT-ERP apoyándose en fuentes documentales: artículos publicados en El Combatiente y en Nuevo Hombre, folletos, volantes, programas y estatutos. Queda pendiente para futuros trabajos el análisis de la

2. POZZI, Pablo, "Por las sendas argentinas..." El PRTERP. La Guerrilla Marxista. Imago Mundi, Buenos Aires, 2004. implementación de dichas políticas, así como los modos en que estas eran vivenciadas por las/os militantes que las encarnaban; trabajos que deberán recurrir a fuentes orales.

\section{Ejército político de las masas: FAS}

La historia escrita del FAS comienza con su IV Congreso, realizado el 18 de agosto de 1973 en el Club Atlético de Villa Luján, Tucumán. Respecto de sus orígenes y trayectoria previa (que podría remitir por lo menos a tres encuentros precedentes) no se han obtenido fuentes, mientras las interpretaciones de diversas/os autoras/es divergen entre sí. La denominación oficial del congreso fue "IV Encuentro Nacional Pro-Formación del Frente Antiimperialista y por el Socialismo", al que asistieron entre 5.000 y 6.000 personas. Entre los oradores, estuvieron Armando Jaime (dirigente del Frente Revolucionario Peronista -FRP-, secretario general de la CGT Salta y presidente del FAS), Agustín Tosco y Leandro Fote. Más que características de congreso, adoptó la forma de acto político, el primero de grandes dimensiones impulsado por el PRT. Uno de los ejes convocantes era lanzar una fórmula clasista y combativa, Tosco - Jaime, con miras a las elecciones de septiembre, pero no pudo efectuarse por la negativa del primero.

En el encuentro participaron más de una decena de organizaciones de izquierda: "Frente Revolucionario Peronista, Partido Comunista Marxista Leninista, Organización Comunista Poder Obrero, Liga Espartaco, Liga Socialista, Movimiento de Izquierda Revolucionaria, Izquierda Socialista, Grupo Praxis, Socialismo Revolucionario, Peronismo 
de Base". También asistieron organizaciones peronistas, entre ellas la Columna Sabino Navarro de Montoneros. Otras figuras que se referenciaron nacionalmente con el FAS fueron Oscar Montenegro (PRT-ERP), Juan Carlos Arroyo (FRP), Silvio Frondizi (Grupo Praxis), Alicia Eguren (FRP), Gregorio Flores (PRT-ERP) y Manuel Gaggero (FRP). ${ }^{4}$ Además, entre las delegaciones provinciales se encontraban: "Neuquén, Santa Fe, Rosario, Corrientes, Jujuy, Salta, Paraná, Córdoba, Capital Federal..., Santiago del Estero, y de la provincia de Buenos Aires..., Chaco, Mendoza y La Rioja" ${ }^{5}$

La experiencia comenzaba de modo positivo, atrayendo a un variado número de organizaciones, así como figuras públicas, con una concurrencia que representaba gran parte de la geografía nacional y un tono combativo expresado en cánticos como: "clasista, obrera, Salta es guerrillera”, "Tosco presidente, del pueblo combatiente", “Tosco, Tosco, Tosco, Tosco corazón, el pueblo te reclama para la revolución". La nota de El Combatiente que ofrecía una crónica del acto, destacaba el carácter de clase con que surgía el Frente, por la primacía de sindicatos y agrupaciones clasistas: "queda clara la hegemonía proletaria

3. PAYO ESPER, Mariel, "El Frente Antiimperialista y por el Socialismo, más que un "ejército político" impulsado por el PRT-ERP”, en Questión, La Plata, 2011, V. I, No 29, p. 3. Disponible en: <http://perio.unlp. edu.ar/ojs/index.php/question/article/view/580/861 >. Sin embargo, en 1973 la Organización Comunista Poder Obrero (OCPO) no existía como tal. Su fundación se dio en 1975 mediante la fusión de varios destacamentos. $\mathrm{La}$ autora se refiere a $\mathrm{El}$ Obrero, uno de los principales afluentes (con desarrollo en Córdoba) que dio vida a la OCPO.

\section{Nuevo Hombre, primera quincena de septiembre de} 1973.

5. El Combatiente, Buenos Aires, 31/08/1973, p. 8.

94 en el mismo en estrecha unidad con amplios sectores populares". ${ }^{6}$

Los tres meses que transcurrieron entre el IV y $\mathrm{V}$ Congreso, fueron aprovechados para estructurar las regionales del FAS, abrir locales y realizar actividades públicas. El primer acto del FAS fue un homenaje al Che Guevara en la Facultad de Filosofía y Letras de la UBA, donde Alicia Eguren, Eduardo Jozami y Ernesto Guevara Lynch hablaron frente a una concurrencia de más de 1500 estudiantes.

E1 V Congreso tuvo lugar el 24 de noviembre de 1973 en Roque Sáenz Peña (Chaco). Al mismo asistieron unas 12.000 personas: estudiantes, obreros y además agrupaciones villeras, delegaciones de aborígenes (tobas, matacos, mocovíes) y mujeres con reivindicaciones propias. Esta vez sí se trató de un congreso, con dos días de trabajo en comisiones y la aprobación de las bases programáticas del FAS, que abordaban la lucha económica, política y democrática con el objetivo de unificar las fuerzas progresistas y revolucionarias. Se afirmaba que el programa estaba abierto, que sufriría modificaciones al ritmo de los cambios en la lucha de clases y de la incorporación de nuevas fuerzas al FAS. En las bases se incluía una serie de reivindicaciones que abogaban por la defensa del trabajo, el salario, las condiciones de salud, vivienda, servicios, educación y cultura. Este congreso tuvo como principales oradores a Tosco y Jaime, pero también hablaron un dirigente toba, el padre Miguel Ramondetti y Alicia Eguren.

E1 VI y último congreso del FAS fue el 15 de junio de 1974, en el club Tiro Federal

6. Ídem, p. 9. 
de Rosario. La concurrencia continuó multiplicándose y esta vez participaron entre 25.000 y 30.000 personas, convirtiéndose en el acto más grande que impulsó el PRT. Nuevamente con la participación de todas las figuras nacionales que integraban la experiencia, a las que se había sumado Rodolfo Ortega Peña. Esta vez hubo más de veinte oradoras/es.

Respecto de la orientación con la que el PRTERP promovió el FAS, en Perspectivas del Frente de Liberación afirmaban que, desde una mirada anticapitalista y antiimperialista, además del partido y el ejército se hacía imprescindible otra herramienta de intervención política: el Frente de Liberación Nacional y Social (FLNS). Esta instancia se constituía en la unión de los sectores explotados -obreros, campesinos, villeros, profesionales, estudiantes e intelectuales- contra el enemigo principal: el imperialismo y sus aliados locales. En defensa de la independencia política de los sectores oprimidos, criticaban los frentes propuestos por la Juventud Peronista (JP) y Montoneros -el Frente Justicialista de Liberación (FREJULI) -, así como por el Partido Comunista (PC) -el Encuentro Nacional de los Argentinos (ENA)-, por sus concesiones a la burguesía que los convertía en propagandistas del nacionalismo burgués. La reivindicación explícita del FAS como la herramienta correcta, no olvidaba advertir que este no constituía propiamente un FLNS. Para ello, tendrían que participar otros partidos y corrientes como los/as socialistas, peronistas, radicales, etc. Por tanto, caracterizaban al FAS como embrión del necesario FLNS. Afirmaban que éste se constituiría en ejército político de las masas, diferenciado del ERP por las características de sus tareas, pero identificado con él en su programa. En cambio, trazaban una precisa distinción con los órganos de masas (sindicatos, organizaciones campesinas, villeras, estudiantiles, etc.). Mientras estos últimos se ocupaban de la lucha reivindicativa y los problemas inmediatos, el Frente debía atender a todos los problemas de las masas, a sabiendas de que son expresiones parciales de una realidad general: el capitalismo imperialista.

E1 FAS combinaba dos niveles de la política perretista. Por un lado, profundizaba la táctica de unidad revolucionaria al sostener un frente en común con otras organizaciones; por otro, forjaba un espacio para la lucha democrática y antidictatorial. El esfuerzo político de unidad por parte del PRT puede apreciarse en el hecho de que, a pesar de que era su principal impulsor y la fuerza con mayor peso numérico en su interior, la presidencia del FAS fue asignada a Jaime.

E1 desenlace del FAS se dio de modo abrupto y dejó abiertos varios interrogantes, puesto que siendo una herramienta a la que el PRT apostaba desde una política frentista y unitaria $\mathrm{y}$ uno de los pilares en que se apoyaba su estrategia revolucionaria, se disolvió luego del masivo congreso de Rosario. Una explicación puede encontrarse en la propuesta perretista de transformar el FAS en un espacio más amplio. Para 1974, el PRT observó que, con la agudización de la lucha de clases, se desarrollaba una vertiginosa derechización del gobierno peronista y un creciente nivel de alianzas con el imperialismo norteamericano. Frente a este panorama, consideró que los márgenes del FAS resultaban estrechos al limitarse a las fuerzas revolucionarias. Entonces, propuso transformarlo en un Frente Democrático Patriótico y Antiimperialista que, con un programa más amplio, fuera 
atractivo para fuerzas progresistas $y$ antiimperialistas. Lo que podría considerarse un análisis acertado, devino en el alejamiento de las fuerzas socialistas, mientras que ninguna de las progresistas recogió la invitación. Luego del VI Congreso, se publicó en Nuevo Hombre la Carta de los compañeros que se retiran del $F A S$, en la que criticaban la línea de Frente de Liberación Nacional por expresar "una posición conciliadora frente al reformismo y sectores progresistas de la burguesía". 7 Según su lectura, la unidad de acción con el reformismo era necesaria, pero no se había llevado a cabo la tarea que permitiera a la militancia del FAS dar la batalla ideológica con estos sectores en defensa de la independencia de clase. En contraposición, ellos/as sostenían que debía constituirse un Frente Revolucionario. ${ }^{8} \mathrm{La}$ salida de este sector, junto con el creciente accionar parapolicial, debilitó al FAS, que no pudo ser sostenido por el PRT ni por el FRP. Luego de esa fecha, sólo se registran algunas declaraciones (como la denuncia del asesinato de Ortega Peña por la Triple A) y actos provinciales, pero ya no se realizó otro congreso nacional y la experiencia se fue diluyendo.

7. Nuevo Hombre, segunda quincena de junio de 1974, p. 23. La carta llevaba la firma de las organizaciones que en breve se fusionarían en OCPO: El Obrero, Organización Revolucionaria Comunista, Organización Revolucionaria Poder Obrero, Movimiento de Izquierda Revolucionaria y Liga Socialista.

8. Estos debates estuvieron presentes desde la fundación del FAS y probablemente signaron contradictoriamente su breve historia. Según recuerda Flores, en el V Congreso en Tucumán "para disgusto de algunos compañeros del PRT, en un comienzo iba a llamarse Frente Popular de Liberación que era la propuesta que traía Mariano (Benito Urteaga). Luis Fabri ..., militante de El Obrero, fue quien propuso que se llamara FAS”. Ver: FLORES, Gregorio, Lecciones de batalla. Una historia personal de los 70, RyR, Buenos Aires, 2006, p. 118.

\section{"Luchar, vencer, obreros al poder": el MSB}

El origen del MSB se encuentra en el Primer Plenario Nacional por la Defensa y la Recuperación Sindical, que se realizó en el Sindicato de Luz y Fuerza de Córdoba el 8 de julio de 1973. La Comisión Organizadora estuvo integrada por Gregorio Flores, ${ }^{9}$ Leandro Fote ${ }^{10}$ y Roberto Campbell. ${ }^{11}$ Con una asistencia de más de mil personas, en representación de agrupaciones sindicales de diversas provincias, se adoptaron resoluciones como el repudio a José Ignacio Rucci ${ }^{12}$ y la defensa de las CGT Regionales combativas (Córdoba, Salta y Río Cuarto), la denuncia del Pacto Social y el reclamo de reincorporación de los despedidos. Entre las decisiones aprobadas, se encontraba la de "construir un Movimiento Sindical de Base que edite un periódico y convoque a un nuevo plenario". ${ }^{13}$ Esta resolución respondía a "la orientación del comité ejecutivo [del PRT] de abril de aquel año de formar un 'Frente Antiburocrático legal' que se opusiera a la 'ofensiva ideológica y propagandística de la burocracia', que impulsara las movilizaciones obreras y que

9. Militante perretista, obrero de Fiat Concord y dirigente del SITRAC (Sindicato de Trabajadores de Concord).

10. Dirigente perretista (proveniente de Palabra Obrera), obrero en el Ingenio de San José de Flores y miembro de la FOTIA (Federación Obrera de los Trabajadores de la Industria Azucarera). Fue elegido diputado obrero por Tucumán en las elecciones de 1965.

11. Dirigente del sindicato de Viajantes en Córdoba.

12. En ese momento, Secretario General de la Confederación General de Trabajadores (CGT), identificado como máximo referente de la burocracia sindical y acusado de ser responsable del asesinato de militantes sindicales combativos.

13. El Combatiente, Buenos Aires, 19/07/1973, p. 12. 
asegurara 'la independencia del movimiento sindical frente al gobierno"'. ${ }^{14}$

En los primeros meses de 1974, se realizó una reunión de la mesa nacional del MSB que evaluó su consolidación en distintas zonas y definió la convocatoria a un nuevo plenario. Se estableció, además, que el mismo debía aprobar una declaración de principios, un programa y conformar una dirección nacional definitiva. Se proponían el ambicioso objetivo de "realización de un congreso nacional de todas las fuerzas sindicales antiburocráticas en un esfuerzo de unidad para ofrecer un frente común a la patronal y la burocracia”. ${ }^{15}$

El plenario del 13 y 14 de abril de 1974, realizado en Córdoba Sport, fue designado II Plenario Nacional del Movimiento Sindical de Base. Según un artículo publicado en $E l$ Combatiente, asistieron representantes de ocho regionales constituidas (aunque sólo menciona siete: Córdoba, Tucumán, Buenos Aires, Rosario, Chaco, Santa Fe y Paraná) y seis en vías de formación (Salta, Jujuy, Formosa, Mendoza, Bahía Blanca y Mar del Plata), reuniendo más de 4.500 personas. Los oradores transmitieron informes de las regionales, enumerando las agrupaciones sindicales que se habían sumado, así como los conflictos en que intervenían. Otros obreros hicieron uso de la palabra, destacándose la intervención de los delegados de Acindar (Villa Constitución), cuya exposición dio cuenta de la experiencia

14. LEIVA FLORES, Sebastián, Teoría y práctica del poder popular: los casos del Movimiento de Izquierda Revolucionaria (MIR, Chile - 1973) y el Partido Revolucionario de los Trabajadores-Ejército Revolucionario del Pueblo (PRT-ERP, Argentina, 1973-1976), Tesis de Maestría, Universidad de Santiago de Chile, 2007, p. 194. 15. El Combatiente, Buenos Aires, 13/03/1974, p. 11. clasista de la que eran protagonistas e hizo foco en la tarea del momento: la unidad.

La política del MSB afirmaba la necesidad de impulsar, de modo articulado, la lucha contra la burocracia sindical y la patronal. Para ello, hacían hincapié en la imprescindible unidad del movimiento obrero y en evitar posicionamientos sectarios. Esta política se sintetizó en su definición "antiburocrática, antipatronal y por la independencia del movimiento obrero del Estado". ${ }^{16}$ No se proponían construir una CGT paralela, lo que significaría dividir al movimiento obrero, sino recuperar los organismos sindicales. En su proyecto de Programa, el MSB denunciaba el Pacto Social, la nueva Ley de Asociaciones Profesionales, la reforma del Código Penal, la intervención de los sindicatos combativos, etc. En cuanto a las reivindicaciones inmediatas, planteaban, entre otras: salario mínimo, vital y móvil; convocatoria a paritarias nacionales; reincorporación de los despedidos por la Ley de Prescindibilidad; control obrero de los ritmos de producción y libertad a los presos políticos. En el II Plenario, se aprobó también un estatuto, se eligió como Secretario General a Eduardo Castello ${ }^{17}$ y se conformó la Mesa Nacional, integrada por quince dirigentes obreros de distintas fábricas del país. En el cierre, hablaron trabajadores de Tucumán, Salta, Mendoza, Chaco y Buenos Aires. Las palabras finales estuvieron a cargo de Tosco en nombre del Movimiento Sindical Combativo (MSC) que nucleaba en Córdoba a doce sindicatos y treinta agrupaciones, destacando que el MSB era uno de sus puntales. Como era

16. El Combatiente, Buenos Aires, 17/04/1974, p. 10.

17. Miembro del Comité Central perretista, obrero de Fiat Materfer y dirigente del SITRAM. 
habitual, cerró su intervención convocando a construir la Patria Socialista.

La concurrencia a estos plenarios nacionales da cuenta de la amplia inserción obrera perretista, no sólo por la cantidad de asistentes, sino también por la variedad de fábricas representadas. Allí se construía una mística propia que abonaba a la consolidación de una identidad combativa. Por ejemplo, "la llegada de la delegación de los trabajadores de Acindar, Metcon y Marathon fue saludada al grito de 'luchar, vencer, obreros al poder". ${ }^{18}$ Hubo unas 120 agrupaciones representadas, mientras la delegación tucumana aportó más de mil obreros que fueron recibidos con el cántico: "A la lata, al latero, los ranchos tucumanos son fortines guerrilleros". En cuanto a la variedad de fábricas, se puede observar el siguiente ejemplo: "la Regional Buenos Aires contó con una cantidad considerable de asistentes, entre los que se encontraban agrupaciones de los establecimientos Rigolleau (Berazategui), SIAP, Fiat (Palomar-Caseros), A.T.E., Imperial Crod, Cildañez (Lugano), EATON (San Martín), Polimene (Ezpeleta), Terrabusi, Metalúrgica Karen, General Motors, Peugeot, TAMET, Kapeluz, Kodak, Miluz, Lamidesc, Matarazzo (Avellaneda), WINCO, INSUD, FATE, Santa Rosa, entre otras, así como también comisiones internas y delegados de distintos lugares de trabajo". ${ }^{19}$

Es difícil detectar el desarrollo fabril específico del MSB, puesto que en los hechos se confundía con el trabajo realizado directamente por

18. Nuevo Hombre, 18/04/1974, p. 4.

19. STAVALE, Santiago, “¿Amplio frente sindical o brazo sindical perretista? Reconstruyendo la trayectoria del Movimiento Sindical de Base", ponencia presentada en VIII Jornadas de Sociología, Universidad Nacional de La Plata, 2014, p. 8. las células partidarias. Mucho del trabajo de inserción obrera perretista desarrollado en los años previos fue volcado hacia la construcción del MSB. Según Pozzi, el origen de este se encuentra en el trabajo sindical del PRT-ERP en las provincias de Córdoba, La Plata, Rosario y Tucumán, aunque su mayor desarrollo se dio en la primera.

Esta apuesta sindical, estuvo signada por una contradicción no resuelta entre crear una herramienta amplia e imponer la hegemonía perretista. Los testimonios aportados por Pozzi, exponen una tensión entre el importante desarrollo sindical impulsado por el PRT-ERP que dio vida al MSB y la estrechez de éste por el férreo control perretista. De Santis confirma el problema y da cuenta de las discusiones al interior del partido. Por ejemplo, relata que, al conformarse la Mesa Nacional del MSB, quedó integrada por doce perretistas y tres aliados. Luego, otras agrupaciones pidieron incluir un representante más por su lado, pero se votó en contra. Santucho fue crítico de esta decisión y planteó que la representación política en la Mesa debería ser inversa, con una minoría de perretistas y una buena cantidad de aliados. ${ }^{20}$ Del MSB participaban otras organizaciones políticas como "el Grupo Obrero Revolucionario (GOR), la 'izquierda socialista', el Partido Comunista Marxista Leninista (PCML), Política Obrera (PO) y el Partido Socialista de los Trabajadores (PST), pero ninguna de ellas estaba representada en la Mesa de dirección. ${ }^{21}$ Esto quedó reflejado en el Boletín Interno $\mathrm{N}^{\circ}$ 61: "en una reunión del comité ejecutivo de junio de 1974 se señaló

20. DE SANTIS, Daniel, La historia del PRT-ERP por sus protagonistas, A formar filas, Buenos Aires, 2010.

21. LEIVA FLORES, Sebastián, Teoría y práctica..., Op. Cit., p. 195. 
que en el frente sindical se había asumido 'un rumbo sectario', lo cual constituía 'una desviación peligrosa de la línea del partido, recordando a sus militantes el 'carácter amplio del movimiento, su funcionamiento legal (y) su iniciativa unificadora', llamándose a corregir esos errores y a avanzar en la conducción del MSB por medio de la capacidad política y no por 'medios administrativos', aquello último en clara alusión al control de la mesa nacional con que había terminado el plenario de abril”. ${ }^{22}$

Las contradicciones internas del MSB no se reducían al hegemonismo perretista. En otros casos, operaban factores relacionados con las características particulares de determinadas agrupaciones de base. Por ejemplo, a pesar de que se había orientado la construcción del MSB en Villa Constitución, allí los/as militantes perretistas integraban la Lista Marrón. Ésta constituía un frente único del que participaban activistas con diversas adscripciones políticas, por lo que poner en pie el MSB en Villa Constitución implicaba competir con la Lista Marrón, que a su vez tampoco podía ingresar al MSB por la variedad de representaciones políticas a su interior.

No obstante, el desarrollo del MSB, como el de todas las experiencias combativas de aquella época, no sólo estuvo signado por sus contradicciones internas, sino también por el creciente accionar represivo. Por ejemplo, la regional Buenos Aires no pudo llevar a cabo su plenario, planificado para el 8 de junio de 1974 en La Matanza, porque la policía impidió el acceso al lugar. Tampoco se realizó el III Plenario Nacional previsto para 1975, ni hay registro en los órganos partidarios del desarrollo de nuevos plenarios zonales. Sin

22. Ídem, p. 205. embargo, durante 1975, el MSB "logró tener distintos niveles de presencia en las luchas obreras y en las coordinadoras interfabriles, sobre todo en la Mesa Previsora [sic] de Gremios en Lucha de Córdoba, desde donde a través del MSC se impulsaron y condujeron las grandes movilizaciones de las automotrices Perkins, Transax, Grandes Motores Diesel y Thompson Ramco". ${ }^{23}$

\section{Una juventud partidaria: la Juventud Guevarista}

Los orígenes de la JG remiten a una resolución del Comité Ejecutivo del PRT de julio de 1973 que orientaba el desarrollo de un trabajo específico hacia la juventud. Medio año más tarde, en enero de 1974, el Comité Central perretista aprobó la creación de una juventud del partido, cuya estructura se regiría por el estatuto partidario. Este recorrido queda reflejado en la "Carta constitutiva de la Juventud Guevarista" que fue publicada en El Combatiente con motivo de informar la realización de su Primera Conferencia Nacional, a principios de 1976, y la convocatoria al Primer Congreso de la JG (sobre cuya realización no se ha encontrado ningún documento, ni testimonio, por lo que es posible que no haya llegado a concretarse). En aquella Conferencia se escogió como símbolo la bandera del Ejército de Los Andes con la cara del Che en el centro. Es decir, una simbología casi idéntica a la del ERP, sólo que reemplazaba la estrella roja por la cara del Che.

La JG no tuvo las mismas características que espacios como el FAS o el MSB, respecto

23. STAVALE, Santiago, “¿Amplio frente sindical...”, Op. Cit., p. 10. 
de la amplitud de su composición, sino que fue proyectada estrictamente como una juventud partidaria. Fue definida como "una organización nacional marxista-leninista que tendrá la misión histórica de dirigir a la Juventud por el camino de la guerra revolucionaria, a la vez de formar la reserva activa de futuros cuadros y militantes de nuestro partido". ${ }^{24}$ En su "Declaración de principios", se pronunciaba anticapitalista y por el socialismo, asumía el reconocimiento del programa perretista y el centralismo democrático como forma de funcionamiento. A instancias de la noción de hombre nuevo del Che, afirmaba la necesidad de una moral revolucionaria y proletaria, a la vez que sostenía un principio internacionalista a través de la Junta de Coordinación Revolucionaria (JCR) y planteaba la necesidad de conformación de un FLNS. En esos términos, la JG constituía un primer escalón para las/os jóvenes que desearan sumarse a la militancia perretista, un espacio de formación como militantes revolucionarias/os.

Señalamos en la introducción la carencia de bibliografía respecto de los frentes de masas del PRT, que en el caso de la JG es nula. A este problema se suma la escasez de fuentes. Sólo tuvimos acceso a tres números de su revista, cuyo nombre era Juventud Rebelde, seguido de la consigna: El presente es lucha, el futuro es nuestro. Estos números corresponden a los meses de mayo, agosto y diciembre de 1976, pero se publicaron como año II, por lo que se puede presumir que la revista comenzó a publicarse en 1975.

De la información obtenida en Juventud Rebelde, se desprende que en "septiembre de

24. El Combatiente, Buenos Aires, 28/01/1976, p. 15.
1973 se realizó la primera reunión nacional de la entonces Juventud del PRT", mientras que recién en julio de 1974 adoptó el nombre de Juventud Guevarista y en noviembre de 1975 se fusionó con el frente universitario. ${ }^{25}$ Además, la JG tuvo Secretario General desde enero de 1975, cuyo cargo fue ocupado por Rodolfo Ortiz (el "Negrito Horacio" o "Raúl”), quien era el responsable de la Juventud del PRT en Capital.

E1PRT orientaba sus esfuerzos específicamente hacia la juventud trabajadora. Al referirse a los sectores en los que debía enfocar su política e inserción, planteaba que la vanguardia se encontraba en:

la juventud obrera de las grandes concentraciones fabriles y luego la juventud que gira alrededor de estas fábricas, como ser los hijos de los obreros de las grandes fábricas, de los colegios subvencionados por estas fábricas, de los barrios circundantes a estas fábricas, de los colegios técnicos, de los colegios secundarios de extracción obrera, de las facultades tecnológicas, de las Universidades determinadas principales, etc. ${ }^{26}$

Incluso después del golpe de 1976, la JG asumía como tarea del momento estrechar su ligazón con la juventud obrera, sobre todo la de las grandes concentraciones fabriles, aunque también buscaba hacer llegar su política a la juventud de los barrios populares.

\section{Frente cultural}

La herramienta promovida por el PRTERP en el ámbito cultural fue el FATRAC.

25. Juventud Rebelde, 04/05/1976, p. 3.

26. El Combatiente, Buenos Aires, 17/12/1976, p. 3. 
No constituyó la única política cultural perretista, pero sí la que fue impulsada desde la dirección partidaria, a diferencia de otros espacios creados por artistas e intelectuales orgánicamente vinculados/as al partido.

Los orígenes del FATRAC se remontan a 1968. Su referente fue el sociólogo Daniel Hopen y lo integraron, entre otras/os, los artistas plásticos Ricardo Carreira, Eduardo Ruano y Eduardo Favario (pertenecientes a los grupos de vanguardia artística de Rosario y Buenos Aires), el escritor Nicolás Casullo y los psicoanalistas Blas de Santos y Martha Rosenberg. Según testimonio de Lindor Bressan, ${ }^{27}$ el FATRAC nucleó "a más de 250 personas que trabajábamos en la cultura: en grupos de teatro, en grupos de cine, en grupos de literatura, en grupos de plásticos". ${ }^{28}$

Las primeras experiencias en las que intervino el FATRAC fueron las acciones de boicot al Premio Broque (1968) por su concepción imperialista y su política de censura. Este fue un "episodio crucial dentro del itinerario de radicalización artística y política de los integrantes de la vanguardia”. ${ }^{29}$ También se hicieron parte de la lucha por la libertad de las/os nueve detenidas/os durante la entrega del premio. El artículo Artistas contra el imperialismo reproduce algunos fragmentos de los volantes repartidos por el FATRAC en

27. Integrante del LTL y militante del PRT-ERP.

28. Mascaró cine americano, Un arma cargada de futuro, Buenos Aires, 2010.

29. LONGONI, Ana, "E1 FATRAC, frente cultural del PRT/ERP”, en Lucha Armada, Buenos Aires, 2005, $\mathrm{N}^{\circ}$ 4, p. 4. Disponible en: <http://www.eltopoblindado. com/files/Articulos/03.\%20Lucha\%20armada\%20y\%20 frentes $\% 20$ culturales/Longoni,\%20Ana.\%20El\%20 FATRAC.\%20Frente\%20cultural\%20del\%20PRT\%20 ERP.pdf>. el Museo Nacional de Bellas Artes durante la inauguración de la exposición Broque. Allí afirmaban: "No estamos dispuestos a avalar ningún proyecto cultural que provenga del fascismo francés ni de ningún otro centro del poder imperialista... No aceptamos ningún tipo de tutelaje económico que convalide el sistema de opresión imperante en el mundo capitalista". ${ }^{30}$

Desde esa perspectiva combatiente contra la lógica del mercado y el imperialismo en el arte y la ciencia, el FATRAC participó de duras polémicas con el "Proyecto Marginalidad", radicado en el Instituto Di Tella y financiado por la Fundación FORD. ${ }^{31}$ Este Proyecto estudiaba las condiciones de marginación social en las poblaciones urbanas y rurales de América Latina. Las/os sociólogas/os que lo integraban, lo hacían desde una perspectiva de los sectores populares. Sin embargo, el FATRAC, junto con otros grupos de intelectuales, les señalaba que ningún producto científico que se pretenda emancipador puede enmarcarse en el camino que ofrecen "los enemigos del pueblo" a riesgo de constituir una actitud colaboracionista.

Ese horizonte político quedó expresado en el documento Los trabajadores de la cultura en el proceso de guerra popular (1971), donde el FATRAC denunciaba el control de la política de investigación por parte de empresas imperialistas a través de fundaciones como Ford o Rockefeller. Afirmaba que la dominación colonial no se ceñía exclusivamente al ámbito económico, sino que

30. El Combatiente, Buenos Aires, 22/07/1968, p. 6.

31. Del que participaban José Nun, Juan Carlos Marín, Miguel Murmis, Ernesto Laclau, Néstor D’Alessio, Beba Balvé y Marcelo Norwersztern. 
se extendía a la producción de conocimiento. El texto desarrollaba un análisis de la situación nacional que adquiría idéntico sentido que el expresado por el PRT-ERP. Caracterizaba al país como capitalista-dependiente, denunciaba la presencia del imperialismo estadounidense y reivindicaba la radicalización de las luchas del pueblo y la clase obrera. Incluso afirmaba: "Ha comenzado en ella [Argentina] el lento y prolongado proceso de guerra popular revolucionaria". ${ }^{32}$ Le reconocía al PRT-ERP un papel de vanguardia y definía la necesidad de que las/os trabajadoras/es de la cultura se incorporaran a la guerra revolucionaria, como ya lo venían haciendo otros sectores del campo popular. La propuesta no se limitaba a los aportes en el ámbito profesional o estético, sino que planteaba el desafío de asumir tareas políticas revolucionarias. Idea que condensaban en la consigna que cerraba el folleto: "Por una cultura militante. Por una militancia combatiente". 33

Otra polémica se dio durante los preparativos de Tucumán Arde y se saldó con la expulsión del FATRAC de aquella experiencia. ${ }^{34}$ Longoni ha interpretado este debate en términos de una diferencia por parte de las/os artistas del Tucumán Arde con los métodos violentos del PRT-ERP y el deseo de que la instancia no fuera copada o manipulada. La escritora López Rodríguez polemiza con esta interpretación, señalando que "los artistas de Tucumán Arde tenían un programa, el del peronismo de

32. FATRAC. Los trabajadores de la cultura en el proceso de guerra popular, Buenos Aires, 1971, p. 1

33. Ídem, p. 6.

34. Exposición artística-política realizada a fines de 1968 en el local de la CGTA de Rosario con motivo de denunciar el cierre de los ingenios azucareros y la represión en Tucumán.

102 izquierda que representaba la CGTA". ${ }^{35}$ Según la autora, lo que Longoni presenta como una intromisión de lo partidario en lo artístico, oculta que "detrás de cada grupo de artistas hay, explícita o implícitamente, programas políticos que se disputan el espacio abierto por la crisis de conciencia en marcha". ${ }^{36}$

En relación al ocaso del FATRAC no existen datos precisos. Longoni identifica 1971 como año de cierre, mientras López Rodríguez afirma que tanto la fecha como los motivos por los que finalizó la experiencia aún son inciertos. Si bien la última publicación firmada por FATRAC es de 1971, el Informe sobre Trelew (1974), lleva la firma de COFAPPEG, el grupo Barrilete y el Frente de Trabajadores de la Cultura (FTC). Sobre esto, López Rodríguez propone dos hipótesis: o se trata de la continuidad del FATRAC, con un cambio de nombre; o es un nuevo frente con una política distinta. En función de una entrevista dada por Gorriarán Merlo, la autora se inclina por la primera opción, pero señalando un cambio de integrantes: "allí donde estaban Hopen y Casullo, encontraremos ahora a Conti, Constantini y Santoro". ${ }^{37}$

\section{Las políticas culturales del PRT-ERP}

\section{Roberto Santoro y el grupo Barrilete}

El grupo Barrilete fue creado en 1963 por

35. LÓPEZ RODRÍGUEZ, Rosana, "La batalla por los héroes. La importancia de la lucha ideológica en la construcción de la fuerza moral", en SARTELLI, Eduardo, GRENAT, Stella, LÓPEZ RODRÍGUEZ, Rosana. Trelew, el informe. Arte, ciencia y lucha de clases: 1972 y después. RyR, Buenos Aires, 2009, p. 54.

36. Ibídem.

37. Ídem, pp. 56-57. 
el poeta Roberto Santoro y desarrolló dos publicaciones que vieron la luz ese mismo año. Por un lado, la revista de poesías Barrilete, y por otro, los Informes. Estos adquirieron un formato distante del tradicional texto informativo. Según Carlos Patiño, ${ }^{38}$ en el grupo se debatía colectivamente un tema sobre el cual todos/as escribían poemas que conformarían el Informe. ${ }^{39}$ Se publicaron: "el Informe sobre Lavorante (junio de 1963), el Informe sobre el desocupado (agosto de 1963), el Informe sobre la esperanza (octubre de 1963), el Informe sobre Discépolo, el Informe sobre Santo Domingo y el Informe sobre el país (1966)." ${ }^{40}$ Luego de una dilatada pausa, el 22 de agosto de 1974 se editó un ejemplar más: el Informe sobre Trelew ${ }^{41}$ Sin embargo, este no contó con el formato de los anteriores (que ya eran poco convencionales). Se trató de un sobre grande del que se extraían poemas, grabados, collages, artículos de diario, la transcripción de la entrevista periodística a los/as militantes en el aeropuerto de Trelew, entre otras expresiones artísticas.

El proceso de politización vivido por Barrilete encontró su principal motor en la persona de Santoro, que ya por 1963 participaba sindicalmente de la Sociedad Argentina de Escritores (SADE), donde se presentó a elecciones en tres oportunidades, pero su lista fue derrotada. Patiño describe el ingreso de Barrilete al FATRAC como resultado de aquel proceso de politización, que también se expresaba en el tono antiimperialista de los Informes y que llevó a varios de sus miembros

38. Integrante de Barrilete.

39. Mascaró cine americano, Un arma cargada..., Op. Cit.

40. LÓPEZ RODRÍGUEZ, Rosana, "La batalla por..., Op. Cit., p. 48.

41. Secuestrado por la Triple A el mismo día que se colocó en los kioscos. a integrarse a las filas perretistas, entre ellos Santoro.

\section{Raymundo Gleyzer y el Cine de la Base}

Otro artista que se vinculó tempranamente al FATRAC y al PRT-ERP, y que desde allí impulsó relevantes experiencias artísticopolíticas, fue el cineasta documentalista Raymundo Gleyzer. En 1970 (año probable de su incorporación al PRT-ERP), sostuvo un diálogo con el director de cine cubano Tomás Gutiérrez Alea, en el que afirmó: "Soy un cineasta argentino y hago films desde 1963. He filmado quince: todos tratan sobre la situación social y política de América Latina. Trato de demostrar que no hay más que un medio de realizar cambios estructurales en nuestro continente: la revolución socialista". ${ }^{42}$ Esta declaración, así como su obra, son testimonio de la experiencia de radicalización política de la que Gleyzer fue parte y que lo llevó a abrazar un proyecto revolucionario. Con su producción ingresó a la gran familia del cine documental latinoamericano de los años '60 y'70. Entre esas obras de enfoque crítico, ya se encontraba México, la revolución congelada (1971) -donde criticaba la traición a los ideales de la Revolución Mexicana y responsabilizaba al PRI (Partido Revolucionario Institucional) por la masacre de Tlatelolco. ${ }^{43}$

42. GLEYZER, Raymundo, Presentación y autocritica en forma de diálogo con Tomás Gutiérrez Alea, 1970. Disponible en: http://www.virnayernesto.com.ar/ VYEART38.htm [Consulta: 5 junio 2016].

43. La película fue prohibida en México y Argentina el mismo día de su estreno. Aquí recién pudo verse en 1973, mientras que en el país azteca se exhibió por primera vez en 2007. 
Como militante perretista, Gleyzer dirigió dos comunicados filmados del ERP, uno llamado Swift, referido al secuestro de Stanley Silvester, y otro sobre el asalto al BANADE. ${ }^{44}$ A comienzos de 1973, fue impulsor de Cine de la Base, concebido como un grupo que no sólo se ocuparía de filmar desde una perspectiva revolucionaria, sino de hacer llegar el cine a la gente, a la base, reproduciendo las películas en barrios, fábricas y universidades, propiciando instancias de debate popular. Según Jorge Denti, ${ }^{45}$ "el concepto de Cine de la Base... era un cine colectivo. Entonces, las funciones eran múltiples: hoy eras camarógrafo, mañana director, pasado mañana productor". ${ }^{46}$ Además de los comunicados del ERP, realizaron filmaciones en los congresos del FAS. Para 1974, existían delegaciones de "Cine de la Base" en La Plata, Bahía Blanca, Trelew, Córdoba, Rosario, Paraná, Corrientes y Chaco. Eran grupos que tenían copias de las películas y las proyectaban como herramienta de militancia.

El cine documental promovido por Gleyzer y el Cine de la Base, se concebía como testimonio de las injusticias padecidas por el pueblo, a la vez que de sus luchas. Desde esa perspectiva filmaron Ni olvido, ni perdón (sobre la Masacre de Trelew) y Me matan si no trabajo y si trabajo me matan (sobre la lucha de los obreros de INSUD, enfermos de saturnismo por la desidia empresarial). En ellas, evidenciaban las condiciones de vida de la clase obrera y denunciaban a los empresarios responsables, así como a funcionarios y burócratas sindicales, a la vez que defendían el socialismo y la lucha armada.

44. Banco Nacional de Desarrollo.

45. Integrante de Cine de la Base.

46. Mascaró cine americano, Un arma cargada..., Op. Cit.
Los films se rodaban en condiciones de extrema clandestinidad. El paradigma en ese sentido fue Los Traidores (1973), su única película de ficción. Es la adaptación de $L a$ Victima, un cuento de Proncet que recrea un hecho verídico: el auto secuestro del dirigente sindical peronista Andrés Framini para ganar unas elecciones internas. La película da cuenta del recorrido de un obrero peronista que a partir de su militancia sindical se convierte en dirigente, devenido en burócrata traiciona a sus compañeros y acuerda con la patronal. El personaje combina las figuras de Augusto Vandor, Lorenzo Miguel y Rucci: una radiografía de la burocracia sindical. La investigación previa incluyó entrevistas a obreros, empresarios y dirigentes sindicales, aguzando el ingenio para resolver problemas de lo más variados, con escasos recursos. Incluso, lograron una entrevista con Lorenzo Miguel simulando ser periodistas holandeses. Las locaciones eran ignoradas por los/as actores/ actrices que eran citados/as en esquinas y recogidos/as por autos que los llevaban hasta el lugar de filmación. Luego, el crudo se envió a EE.UU. donde un amigo se ocupaba de la postproducción, que no podía realizarse en Argentina por la censura. Los envíos se hacían a través de pilotos de Aerolíneas Argentinas que sacaban el material en sus valijas, sin que pasaran por Aduana.

El último film de Cine de la Base fue rodado en 1979 por los sobrevivientes exiliados. Con el título Las tres $A$ son las tres armas y sobre la base del texto de la carta de Rodolfo Walsh, denunciaron el terrorismo de Estado en Argentina. 


\section{Libre Teatro Libre}

El LTL fue un elenco cordobés conformado por la dramaturga María Escudero y algunas/ os de sus estudiantes, varias/os de las/os cuales se integraron al PRT-ERP. Las búsquedas artístico-políticas que lo motorizaron tienen en común con las anteriores la preocupación por lo colectivo y por la circulación de la producción. En palabras de Roberto Videla ${ }^{47}$ : "a nosotros no nos interesaban los autores, ni tampoco los directores. Era horizontal el trabajo. Era experiencia de creación colectiva y de dirección colectiva” ${ }^{48}$ Bressan sintetiza:

Nos habíamos planteado... una revolución en la forma de hacer teatro y en los contenidos del teatro. Nosotros sabíamos que no queríamos hacer un teatro formal, dentro de la institución del teatro, donde la gente iba al teatro. Queríamos sacar el teatro de ese ámbito, ya que lo considerábamos muerto, y llevarlo a lugares donde estaba la gente, donde estaban los sectores populares, donde estaba la gente que luchaba, donde estaba la gente que nunca iba al teatro. ${ }^{49}$

El repertorio del LTL era fiel testimonio de su compromiso con los sectores populares. $\mathrm{Su}$ primera obra fue "El asesinato de X" (1970). Desde la creación colectiva, contaron la historia de un dirigente sindical asesinado por la represión. En 1973, el LTL viajó a Tucumán por invitación del PRT-ERP y allí crearon una obra en la que contaban la lucha contra el cierre de los ingenios azucareros.

$\overline{\text { 47. Integrante del LTL. }}$

48. Mascaró cine americano, Un arma cargada..., Op. Cit. 49. Ibídem.
Escritores

Otros intelectuales que se sumaron a las filas perretistas fueron los escritores Haroldo Conti y Humberto "Cacho" Constantini. Según Mattini, estos compartieron célula partidaria con Santoro. ${ }^{50}$ Uno y otro hicieron emerger su compromiso político en su obra literaria: Conti en Mascaró, cazador americano (1975) y Constantini en De dioses, hombrecitos $y$ policías (1979), escrita en los primeros años de dictadura y marcada por el exilio. Ambas novelas recibieron el Premio Casa de las Américas, del que además Conti fue jurado en 1971 y 1974. Los tres escritores que integraban la célula perretista realizaron sus aportes para el Informe sobre Trelew: Santoro, una poesía; Constantini, un cuento; Conti, un relato testimonial.

Entre sus tareas políticas, Constantini fue parte de las listas gremiales de las que participó Santoro en la disputa por la SADE. Incluso, en 1973 fue candidato a presidente de la misma, aunque, como ya se ha dicho, no lograron alzarse con el triunfo. Del testimonio de Denti emerge que Conti jugó un rol de enlace entre Cine de la Base, los otros grupos de artistas e intelectuales y el PRT-ERP. Esto puede observarse en la revista Crisis, donde Conti publicaba artículos sobre literatura, obras del LTL y encuentros del FAS. Según Ana María Sívori (militante perretista), cuando lo secuestraron era el responsable de la interferencia de Radio Colonia, la primera interferencia promovida por el PRT-ERP. ${ }^{51}$

50. REDONDO, Nilda, Haroldo Conti y el PRT: arte y subversión. Ediciones Amerindia, Buenos Aires, 2004, p. 55.

51. Mascaró cine americano, Un arma cargada..., Op. Cit. 
En el marco de los debates en torno del papel del escritor revolucionario, Santoro, Conti y Constantini asumieron un compromiso que no sólo fue escritural y de apoyo a las luchas populares, sino que fue orgánico con un proyecto de revolución social. Su literatura constituyó un arma crítica, apuntalando otros contenidos y cuestionando convenciones estéticas. Pero su perspectiva revolucionaria emergió principalmente en su praxis. Concibiéndose trabajadores de la cultura, desarrollaron una militancia sindical. Su desempeño como periodistas también da cuenta de la apuesta por brindar testimonio de la explosión que se producía en el ámbito cultural como en todos los sectores populares.

\section{Reflexiones en torno a la politica cultural perretista}

En el análisis de estas experiencias, puede observarse el desarrollo de un movimiento dialéctico por el cual numerosas/os artistas e intelectuales vivenciaron un proceso de radicalización y encontraron en el proyecto perretista su espacio político. Simultáneamente, dentro del partido ejercieron su propia influencia, lo que redundó en el desarrollo de nuevos espacios y la incorporación de otras/os artistas e intelectuales. Por ello, las propuestas culturales promovidas por perretistas son consideradas como política del PRT-ERP, aunque no hayan sido originadas por iniciativa de la dirección partidaria. Estas políticas culturales son resultado, en parte, de lo que los/as artistas perretistas pensaban sobre la articulación entre arte y política.

La amplia producción (desde comunicados y cortos hasta poemarios, cuentos, testimonios) se dio en el marco de un proceso colectivo, determinado por las condiciones de la lucha revolucionaria y marcado por la necesidad de repensar la función del arte y la literatura en relación con el proyecto político socialista. Varios testimonios de artistas perretistas dan cuenta de que la dirección partidaria no interfería en los procesos creativos. Bressan afirma que nadie del PRT le planteaba al LTL lo que debían transmitir sus obras, en todo caso sí discutían dónde presentarlas. Respecto del Cine de la Base, Barberis relata que "el hecho de hacer los comunicados, era una decisión nuestra de que había que propagandizar a través del medio audiovisual. No había una orientación: 'hagan tal cosa'. Sino que nosotros decíamos 'hay que hacer tal cosa" ${ }^{52}$ Simultáneamente, señalan que no se los/as obligó a proletarizarse en una fábrica, sino que construyeron la noción de "trabajador/a de la cultura”.

En estas experiencias, identificamos factores comunes que pueden ser leídos como un programa político-cultural. Considerarse trabajadores/as de la cultura implicaba una perspectiva clasista, una política de sindicalización y una concepción de integración con otros sectores populares. El contenido de sus productos apuntaba a la crítica social, a dar testimonio de las luchas, así como denuncia de situaciones injustas; productos pensados para constituirse en herramientas promotoras de debates, organización y luchas. Ponían en cuestión el contenido, pero también las formas tradicionales, ensayando innovaciones estéticas. En cuanto a la creación, desarrollaban una preocupación por lo colectivo, de tal modo que todos los grupos ponían en cuestión los roles fijos de escritura, dirección, vestuario,

52. Ibídem. 
etc., en una asunción colectiva de las tareas. La inquietud no se circunscribía exclusivamente al momento de creación. Es claro el desvelo por asegurar la circulación masiva de los productos, hacerlos llegar a los sectores populares. Esto implicó una ruptura con las instituciones tradicionales. En definitiva, sus búsquedas no se orientaban a hacer más accesible a las masas el arte burgués. Por el contrario, apostaron a crear un arte revulsivo, capaz de cuestionar el orden establecido.

Estas prácticas político-culturales se enmarcaban en una experiencia latinoamericana que tuvo su referencia paradigmática en el "boom literario". No obstante, su condición de posibilidad no se encontraba exclusivamente en aquella estructura de sentimiento, sino también en los debates propios de la tradición marxista que ha dedicado no poco de su atención a las relaciones entre arte y revolución. Gleyzer lo expresaba con estas palabras, en una carta un amigo mexicano (1971):

plantearse un cine concientizador tiene su mérito, pero más lo tiene cuando el cineasta como revolucionario se incorpora a una estructura revolucionaria. No creo en el cine revolucionario, creo firmemente en la Revolución... no me interesa tanto el elemento cultural que pueda irradiar una obra tercermundista sino su instrumentación política, con la Revolución, desde dentro de la Revolución. Pero, ojo: no la Revolución en abstracto, la Revolución que nos gustaría, sino la que uno, como ser humano, hace. $\mathrm{O}$ te juegas entero por la Revolución Socialista o te dedicas a realizar un cine tercermundista y andas escribiendo tu idea sobre lo que hay que hacer, sin hacerlo personalmente". ${ }^{53}$

53. PEÑA, Fernando y VALLINA, Carlos, "El cine como arma. Raymundo Gleyzer y los comunicados del
Ya desde el FATRAC convocaban a los/as trabajadores/as de la cultura a incorporarse a la guerra revolucionaria y hacían énfasis en que los/as artistas no debían sobrevalorarse. Cuestionaban a quienes veían la vanguardia revolucionaria en minorías intelectuales y no en el proletariado. Afirmaban que "si bien la crítica ideológica es válida y necesaria, las transformaciones de las estructuras políticassociales-económicas, pasa por carriles políticos". 54 En este aspecto, no cabe sino reconocer que los/as intelectuales y artistas perretistas seguían al pie de la letra la célebre tesis marxista: "Los filósofos no han hecho más que interpretar de diversos modos el mundo, pero de lo que se trata es de transformarlo". ${ }^{55}$

\section{Conclusiones}

La reconstrucción histórica de las herramientas con las que el PRT-ERP intervino en los distintos escenarios de la vida social y política permite observar que la organización destinó buena parte de su esfuerzo al desarrollo de experiencias de organización entre los sectores populares, proporcionando una descripción densa de los límites y presiones bajo los cuales se elaboraba la línea partidaria. Este análisis se contrapone a las interpretaciones (tributarias de la memoria Nunca más) que representan al PRT-ERP como una organización militarista,

ERP (1971-1972)", en Razón y Revolución , Buenos Aires, 1998, N 4, p. 2. Disponible en: <http://www. razonyrevolucion.org/textos/revryr/arteyliteratura/ ryr4Pena.pdf>.

54. FATRAC. Los trabajadores de la cultura..., Op. Cit., p. 6.

55. MARX, Carlos, “Tesis sobre Feuerbach”, en MARX, Carlos y ENGELS, Federico, Obras escogidas, Cartago, Buenos Aires, 1957, p. 714. 
aislada de las masas que protagonizaban la escena de la lucha de clases. ${ }^{56}$

La puesta en pie del FAS expresa una visión amplia de la lucha revolucionaria. Si al partido proletario le correspondía la dirección y al ejército popular la lucha armada, el PRT-ERP apostó a la construcción de un frente político con otras organizaciones del campo popular. Aunque la participación electoral fue una de las apuestas, no constituyó su objetivo exclusivo. La razón de ser del FAS obedecía a una mirada estratégica sobre la composición social argentina con el propósito de tejer alianzas con los diversos actores políticos que jugarían un rol destacado en la lucha revolucionaria.

Por su parte, la constitución del MSB, resultado de una política de inserción obrera, da cuenta de la centralidad que se asignaba a la clase obrera. Distante de las interpretaciones que presentan al PRT-ERP como expresión de una juventud de clase media radicalizada, existe evidencia de una praxis que centraba sus esfuerzos en el proletariado. En este sentido, no sólo el desarrollo del MSB, sino la política con la que se orientó a la JG, al FATRAC $\mathrm{y}$ otras herramientas culturales, demuestra que los esfuerzos militantes se dirigían de modo integral a la inserción en sectores de trabajadores/as.

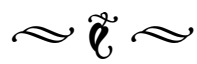

56. SEOANE, María, Todo o nada. La bistoria secreta y politica del jefe guerrillero Mario Roberto Santucho, Planeta, Buenos Aires, 1991. LONGONI, Ana, "La pasión según Eduardo Favario. La militancia como ética del sacrificio", en El Rodaballo, Buenos Aires, 2000, No 11/12, año VI.

CARNOVALE, Vera, Los combatientes. Historia del PRTERP, Siglo XXI, Buenos Aires, 2011. 


\section{Bibliografía}

CARNOVALE, Vera, Los combatientes. Historia del PRT-ERP, Siglo XXI, Buenos Aires, 2011.

DE SANTIS, Daniel, La historia del PRT-ERP por sus protagonistas, A formar filas, Buenos Aires, 2010.

FLORES, Gregorio, Lecciones de batalla. Una historia personal de los 70. RyR, Buenos Aires, 2006.

LEIVA FLORES, Sebastián, Teoría y práctica del poder popular: los casos del Movimiento de Izquierda Revolucionaria (MIR, Chile-1973) y el Partido Revolucionario de los Trabajadores - Ejército Revolucionario del Pueblo (PRT-ERP, Argentina, 1973-1976), Tesis de Maestría, Universidad de Santiago de Chile, 2007.

LONGONI, Ana, "El FATRAC, frente cultural del PRT/ERP”, en Lucha Armada, Buenos Aires, 2005, $\mathrm{N}^{\circ}$ 4. Disponible en: <http://www.eltopoblindado.com/files/Articulos/03.\%20Lucha\%20armada\%20 y\%20frentes\%20culturales/Longoni,\%20Ana.\%20E1\%20FATRAC.\%20Frente\%20cultural\%20del\%20 PRT\%20ERP.pdf>.

LÓPEZ RODRÍGUEZ, Rosana, "La batalla por los héroes. La importancia de la lucha ideológica en la construcción de la fuerza moral”, en SARTELLI, Eduardo, GRENAT, Stella, LÓPEZ RODRÍGUEZ, Rosana. Trelew, el informe. Arte, ciencia y lucha de clases: 1972 y después, RyR, Buenos Aires, 2009, pp. 45-64.

MARX, Carlos, “Tesis sobre Feuerbach”, en MARX, Carlos y ENGELS, Federico, Obras escogidas, Cartago, Buenos Aires, 1957, pp. 713-714.

MATTINI, Luis, Hombres y mujeres del PRT-ERP: De Tucumán a la Tablada, De la Campana, La Plata, 2007.

PAYO ESPER, Mariel, "El Frente Antiimperialista y por el Socialismo, más que un "ejército político" impulsado por el PRT-ERP”, en Questión, La Plata, 2011, V. I, N² 29, 2011. Disponible en: <http:// perio.unlp.edu.ar/ojs/index.php/question/article/view/580/861>.

PEÑA, Fernando y VALLINA, Carlos, "El cine como arma. Raymundo Gleyzer y los comunicados del ERP (1971-1972)”, en Razón y Revolución N 4, Buenos Aires, 1998, pp. 1-14. Disponible en: <http:// www.razonyrevolucion.org/textos/revryr/arteyliteratura/ryr4Pena.pdf>.

POZZI, Pablo, “Por las sendas argentinas...” El PRT-ERP. La Guerrilla Marxista, Imago Mundi, Buenos Aires, 2004.

REDONDO, Nilda, Haroldo Conti y el PRT: arte y subversión, Ediciones Amerindia, Buenos Aires, 2004.

SEOANE, María, Todo o nada. La historia secreta y politica del jefe guerrillero Mario Roberto Santucho, Planeta, Buenos Aires, 1991.

STAVALE, Santiago, “¿Amplio frente sindical o brazo sindical perretista? Reconstruyendo la trayectoria del Movimiento Sindical de Base”, ponencia presentada en VIII Jornadas de Sociologí, Universidad 
Nacional de La Plata, 2014.

TILLET, Agustín, “La Cultura como campo de batalla: el PRT-ERP”, ponencia presentada en VI Jornadas de Sociologia, Universidad Nacional de La Plata, 2010. 